\title{
Feasibility study of a hybrid plants (photovoltaic-LPG generator) system for rural electrification
}

\author{
Mabrouk Adouane ${ }^{*}$, Ismail Tabet, Daoud Rezzak, Khaled Touafek, Sitayeb Abdelkader, and Houam Yahia \\ Unité de Recherche Appliquée en Energies Renouvelables, URAER, Centre de Développement des Energies Renouvelables, \\ CDER, 47133 Ghardaïa, Algeria
}

\begin{abstract}
The present study investigates the possibility of using a stand-alone photovoltaic/LPG (liquid petroleum gas) generator hybrid power system for low-cost electricity production which can satisfy the energy load requirements of a typical remote and isolated rural area. In this context, the optimal dimensions to improve the technical and economical performances of the hybrid system are determined according to the load energy requirements. The proposed system's installation and operating costs are simulated using the Hybrid Optimization Model for Electric Renewable (HOMER), the solar radiation and the system components costs as inputs; and then compared with those of other supply options such as diesel generation.
\end{abstract}

\section{Introduction}

The lack of an electrical network in remote areas and the prohibitively high connection cost of grid extension and rough topography often lead to exploration of other options. Today, the diesel generator is the most used for decentralized electrification [1]. Nevertheless, the fuel supply costs are very high and gradually increase with distance.

Algeria has recently launched a major program in renewable energy [2]; we had to find a way to replace the generators that are used in our desert regions. Ghardaïa $\left(32^{\circ} 26^{\prime} \mathrm{N} 03^{\circ} 46^{\prime} \mathrm{E}\right)$ with an annual average solar radiation estimated to $4.98 \mathrm{kWh} / \mathrm{m}^{2} /$ day $[3,4]$ is blessed with renewable energy resources which can be properly utilized for electricity generation. Thus reduce not only the dependence of electricity generation on conventional fuel but also the emissions of greenhouse gases.

The hybrid systems photovoltaic/generators offer a real advantage for decentralized rural electrification. They assure savings in costs [5] compared to single source of energy solutions. The design of hybrid systems and their technical and economic optimization $[6-9]$ is significantly more complex, it requires a precise analysis of multiple parameters and factors that can influence the performance and competitiveness of the system. Several search works has been carried out on hybrid systems with respect the performance, optimization and other parameters of importance.

The present study investigates the possibility of using a stand-alone photovoltaic/LPG (liquid petroleum gas) generator hybrid power system for low-cost electricity production to satisfy the energy load requirements of a remote and isolated area in Algeria. In this context, the

\footnotetext{
* e-mail: adouanemabrouk@yahoo.fr
}

dimensions of the hybrid system are determined according to the availability of the photovoltaic energy resources and the load energy requirements. Thereafter economic performance of the system is compared with that of other supply options such as diesel generation.

\section{Demand analysis}

The proposed hybrid system is supposed to supply a domestic load. Households in rural areas of Ghardaïa [4] are simple and do not require large amounts of electrical energy for lighting, cooking and entertaining. The determination of the load is one of the most important steps in the design of hybrid energy systems. In this study, a hypothetical home model of a family composed of seven (07) members is considered.

To consume the least amount of energy and reduce the size of the photovoltaic system, we choose the low consumption equipment. These loads are based primarily on: the energy saving lamps (5 fluorescent light bulbs, $23 \mathrm{~W}$ each), 2 fans (usually ceiling fan, $60 \mathrm{~W}$ each) and a television (TV, $60 \mathrm{~W}$ ). The electricity requirement for lighting is not the same, with an increase during winter due to timing of sunset and sunrise. Fans are used only in summer, normally at night, with an operating time estimated $4 \mathrm{~h}$ /day. Average TV operating time is $5 \mathrm{~h}$ per day. The primary load or energy consumption pattern usually varies over $24 \mathrm{~h}$ and over different months of the year. Figure 1 shows two load profiles on a day of summer (April-October) and winter (November-March).

We can see that the demand for electricity varies throughout the day. In the morning (6:00 to 8:00) and lunch (11:00 to 13:00), family members are at home for breakfast, lunch and rest, an increases electricity demand is observed. The maximum demand occurs at night (17:00 to 21:00) where a large part of equipments are connected. 

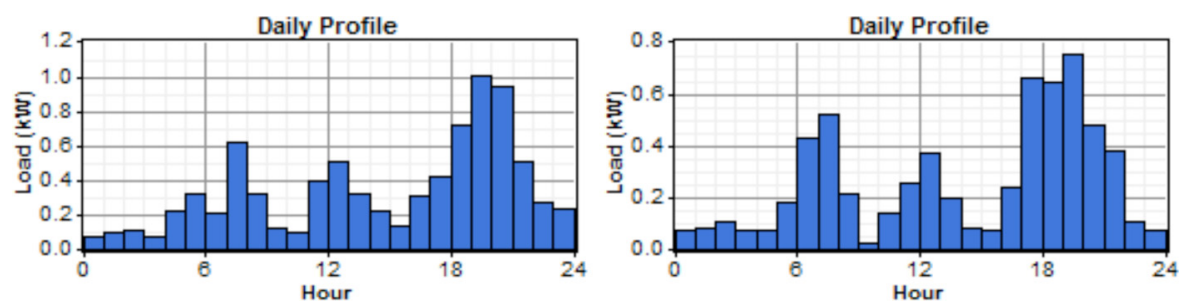

Fig. 1. Load profile on winter (November-March) and summer (April-October).
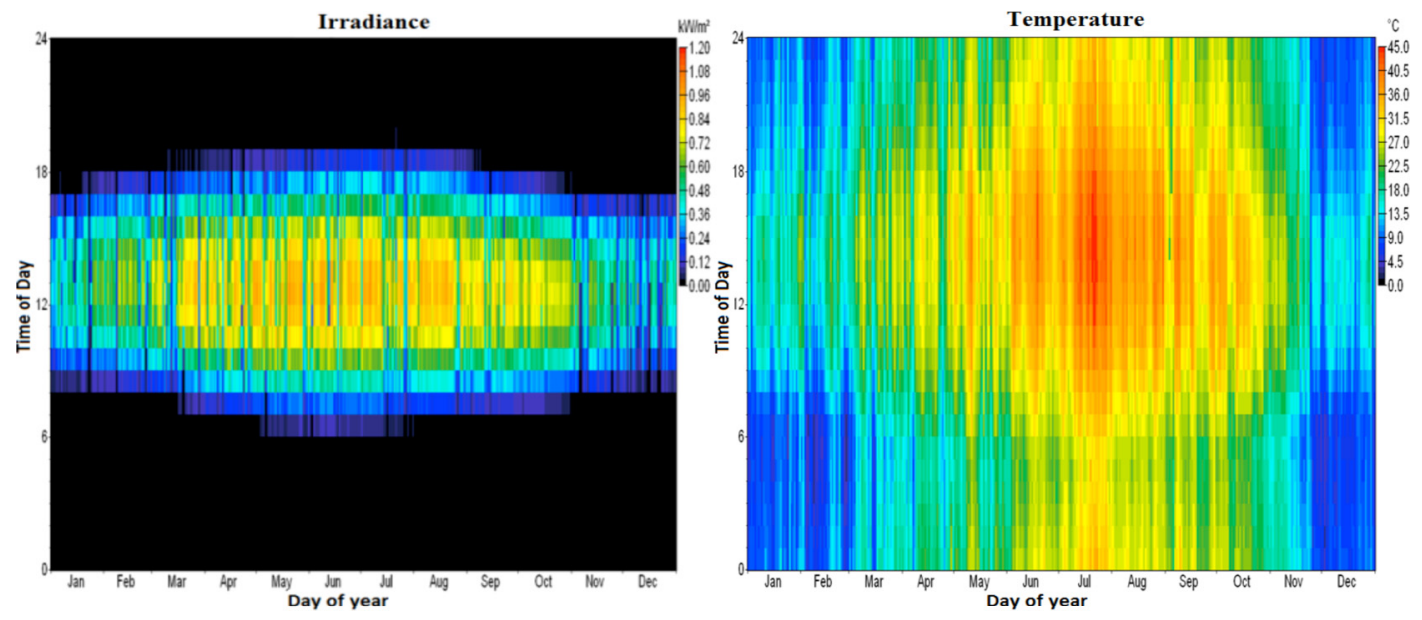

Fig. 2. Variations of irradiance and temperature.

\section{Solar energy potential}

Algeria experiences some of the highest levels of solar radiation in the world, the average daily solar radiation varies between $4.5 \mathrm{kWh} / \mathrm{m}$ and $6.5 \mathrm{kWh} / \mathrm{m}$. The annual averages of irradiance are available from the Institute. The meteorological data (irradiance and temperature) in the entire year of 2013 was measured at the Unit of Applied Research in Renewable Energies (URAER) that is located in Ghardaïa city. As shown in Figure 2.

The solar radiation data for the selected remote area was estimated to range between $2.35 \mathrm{kWh} / \mathrm{m}^{2} /$ day and $6.86 \mathrm{kWh} / \mathrm{m}^{2} /$ day with an average annual solar radiation estimated to $4.98 \mathrm{kWh} / \mathrm{m}^{2} /$ day. It can be noticed that more solar irradiance can be expected from the month of May to August while less solar irradiance is to be expected from November to February.

The average temperature is a variable climate with a significant impact on the behavior of equipment. The analysis of this data is crucial. It is observed in Figure 2, winter temperatures range between $7^{\circ} \mathrm{C}$ and $21^{\circ} \mathrm{C}$. They climb to $35^{\circ} \mathrm{C}$ in May to reach an average of $40^{\circ} \mathrm{C}$ in July and August. Mercury can rise up to $45^{\circ} \mathrm{C}$ and beyond during heat waves.

\section{Hybrid renewable system configuration}

The economic study is performed on the HOMER software; it allows us to compare the financial and technical constraints on the use of two different types of generators technologies (Diesel and LPG) on the operating costs. We present in Figure 3 the relative diagram HOMER program adopted for the hybrid system.

The autonomous hybrid $\mathrm{PV} /$ generator power system considered is a combination of $\mathrm{PV}$ array, generator and battery bank, DC/AC inverter, controller and other accessory devices and cables. According to such a block diagram, PV array, battery bank and DC load are all connected through an intermediate DC bus, the last in turn connected to the $\mathrm{AC}$ load through a $\mathrm{DC} / \mathrm{AC}$ inverter and distribution network.

The PV array work to satisfy the DC load and AC load demands. When the output power of the PV array, which depends on the solar radiation variations, is abundant, the generated power, after satisfying the load demand, will be supplied to feed the battery bank until it is fully charged. On the contrary, during the nights or days with low sunlight, the output power is poor; the battery bank will release power to assist the hybrid system to meet the load requirements until the battery bank is depleted then the generator starts.

\section{System description and components}

The various components of hybrid photovoltaic system are introduced into the HOMER software with technological availability options, component cost and availability of resources. The technical and economic parameters of the various components of the hybrid system adopted are shown in Table 1. 


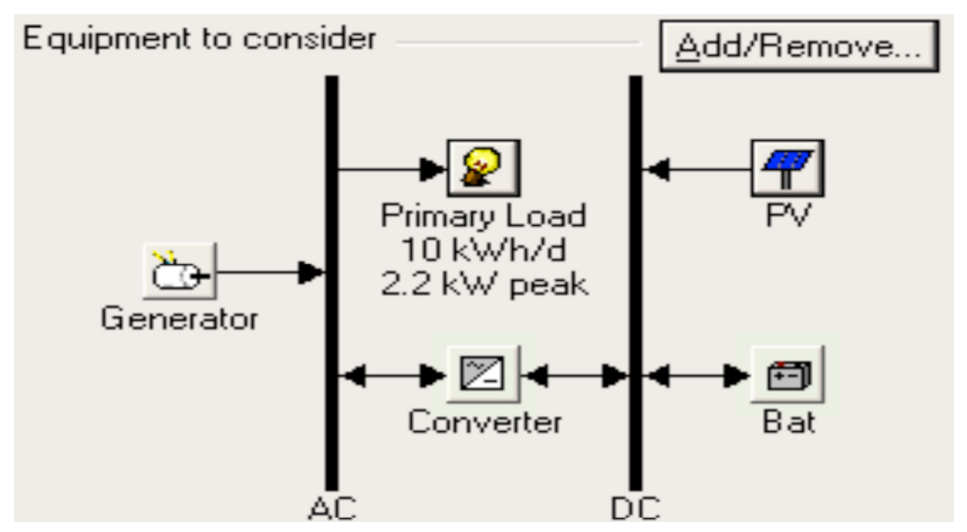

Fig. 3. Configuration of hybrid $\mathrm{PV} /$ generator system in HOMER software.

Table 1. Technical parameters and cost of components.

\begin{tabular}{|c|c|c|c|}
\hline & Parameters & Unit & Value \\
\hline \multirow{5}{*}{ PV Module } & Rated capacity & $\mathrm{kW}$ & 1.04 \\
\hline & Capital cost & $\$$ & 5000 \\
\hline & Replacement cost & $\$$ & 3400 \\
\hline & Operation and maintenance cost & $\$ /$ year & 20 \\
\hline & Lifetime & year & 25 \\
\hline \multirow{8}{*}{ Batteries } & Nominal voltage & Volt & 12 \\
\hline & Nominal capacity & $\mathrm{Ah}(\mathrm{kWh})$ & $100(1.2)$ \\
\hline & Minimum state of charge & $\%$ & 30 \\
\hline & Capital cost & $\$$ & 180 \\
\hline & Replacement cost & $\$$ & 180 \\
\hline & Operation and maintenance cost & $\$ /$ year & 5 \\
\hline & Minimum battery life & year & 4 \\
\hline & Quantity & - & 6 \\
\hline \multirow{6}{*}{ Converter } & Rated capacity & $\mathrm{kW}$ & 2.5 \\
\hline & Efficiency & $\%$ & 94 \\
\hline & Capital cost & $\$$ & 1500 \\
\hline & Replacement cost & $\$$ & 1500 \\
\hline & Operation and maintenance cost & $\$ / \mathrm{kW} /$ year & 10 \\
\hline & Lifetime & year & 10 \\
\hline \multirow{5}{*}{ Diesel generator } & Rated capacity & $\mathrm{kW}$ & 3.5 \\
\hline & Capital cost & $\$$ & 1450 \\
\hline & Replacement cost & $\$$ & 1300 \\
\hline & Operation and maintenance cost & $\$ / \mathrm{h}$ & 0.3 \\
\hline & Life time operating & $\mathrm{h}$ & 10,000 \\
\hline \multirow{5}{*}{ LPG generator } & Rated capacity & $\mathrm{kW}$ & 3.5 \\
\hline & Capital cost & $\$$ & 1150 \\
\hline & Replacement cost & $\$$ & 1050 \\
\hline & Operation and maintenance cost & $\$ / \mathrm{h}$ & 0.2 \\
\hline & Life time operating & $\mathrm{h}$ & 12,000 \\
\hline
\end{tabular}

The cost of generator depends on its size and the fuel used. The generator fuel is modeled by a linear curve which is characterized by a slope and an intercept coefficient. In this study two different generators are considered, diesel and gas butane. The default slop and intercept coefficients are $0.234 \mathrm{l} / \mathrm{h} / \mathrm{kW}$ and $0.244 \mathrm{l} / \mathrm{h} / \mathrm{kW}$ respectively for the Diesel generator, $0.108 \mathrm{~kg} / \mathrm{h} / \mathrm{kW}$ and $0.124 \mathrm{~kg} / \mathrm{h} / \mathrm{kW}$ respectively for the butane gas generator. Table 1 represents different cost parameters of generators. 


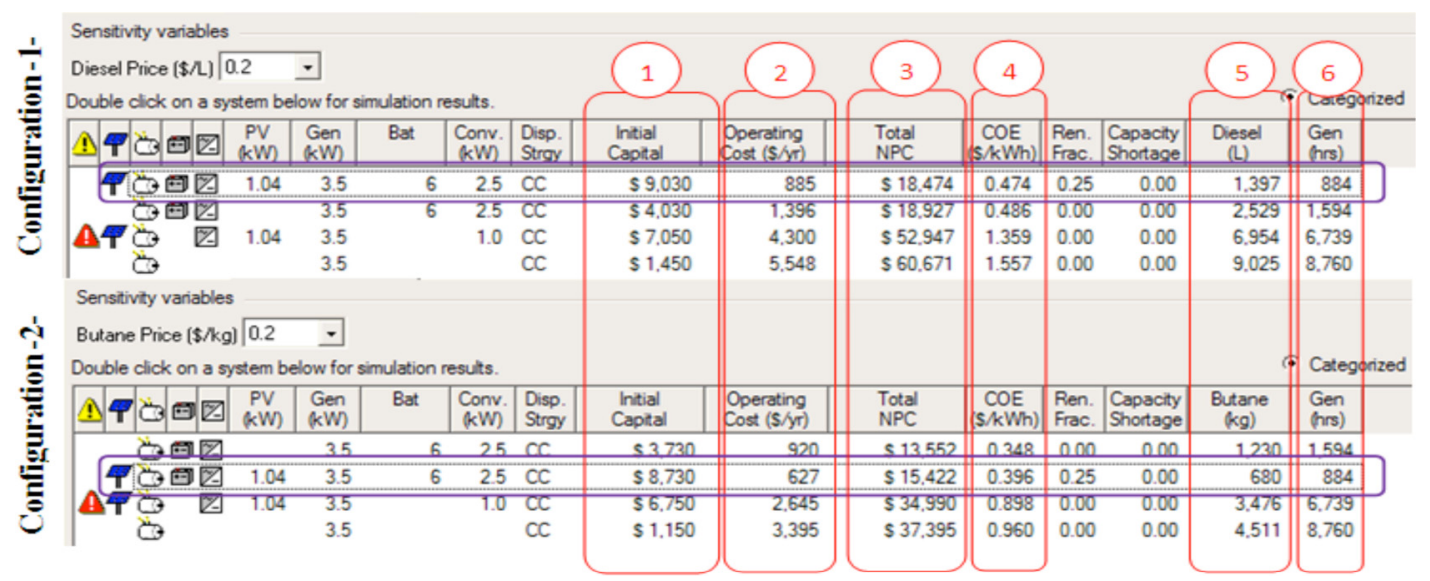

Fig. 4. Impact of generator technology on costs.

\section{Results and discussions}

Energy balance calculations are performed for each configuration of the considered hybrid photovoltaic system. The configurations obtained are selected according to their feasibility, the cost of installation. The profitability of the operation is evaluated on the life of the project, estimated a priori to 25 years. The calculations of the cost of hybrid system take into account costs such as capital and interest, depreciation, operating costs, maintenance and fuel. HOMER produced results that we can show as possible configurations list sorted by cost lifecycle (net present cost NPC). It also displays simulation results in tables and graphs. We show in Figure 4 the results obtained for a photovoltaic hybrid system with two types of generator:

- configuration -1-: Hybrid system with a diesel generator; - configuration -2-: Hybrid system with a LPG generator. that:

In analyzing the different points in Figure 4, we find

- in configuration -1-, the hybrid system, which combines photovoltaics with a diesel generator, is favored over other combinations, because of the low cost per $\mathrm{kWh}$ produced which is estimated at $\$ 0.474$;

- in configuration -2-, the hybrid system, which combines the generator gases with batteries is favored over other combinations, because of the low cost per $\mathrm{kWh}$ produced which is estimated at $\$ 0.348$ (4). Despite its high initial cost estimated at $\$ 8730$, it favors the hybrid system combining solar with a gas generator; because it reduces the operation time of the generator $710 \mathrm{~h}$, so it saves fuel and reduces pollution;

- the initial investment cost is $\$ 9030$ for diesel configuration, whereas it is $\$ 8730$ for the LPG configuration, which is due to the acquisition price of different types of generator, with $\$ 1450$ for the diesel generator against $\$ 1150$ for the LPG generator;

- for the same period of operation of $884 \mathrm{~h}$ (6); diesel generator consumes 1,397 liters of fuel, whereas the generator gases consumes $680 \mathrm{~kg}$ of gas (5), which directly influences the cost of operating the system with $\$ 885 /$ year for the configuration -1 - and $\$ 627 /$ year for
Table 2. Annual energy produced.

\begin{tabular}{llr}
\hline Production & $\mathrm{kWh} /$ year & $\%$ \\
\hline Photovoltaic & 1946 & 42 \\
Generator & 2646 & 58 \\
Total & 4592 & 100 \\
\hline
\end{tabular}

configuration -2- with a spread of $\$ 258 /$ year (2). This results in a cost of electricity produced $\$ 0.474 / \mathrm{kWh}$ for the first configuration against $\$ 0.396 / \mathrm{kWh}$ for the second (4); and

- the total cost of the system (3) is higher in the configuration -1- with a total cost of $\$ 18,474$ against $\$ 15,442$ for the configuration -2- in economy carry a $\$ 3,032$ (3) throughout the operation system.

\section{Technical and environmental analysis of the system}

For each of these possible solutions, HOMER provides all the operating parameters of the components and the entire system (the total energy produced, proportion of renewable energy and emissions of air pollutants...).

\subsection{Electric power generation}

Energy production over a year is detailed in Table 2.

Production systems involving the following fractions described in the table and that show significant participation of the photovoltaic source that reaches $42 \%$.

\subsection{Distribution of installation costs}

The evaluation of the total project cost for the three configurations considered is shown in Figure 5.

The diesel generator has the highest cost (about double that of the photovoltaic or gas generator and three times that of batteries), this is due to high fuel prices and maintenance costs. 

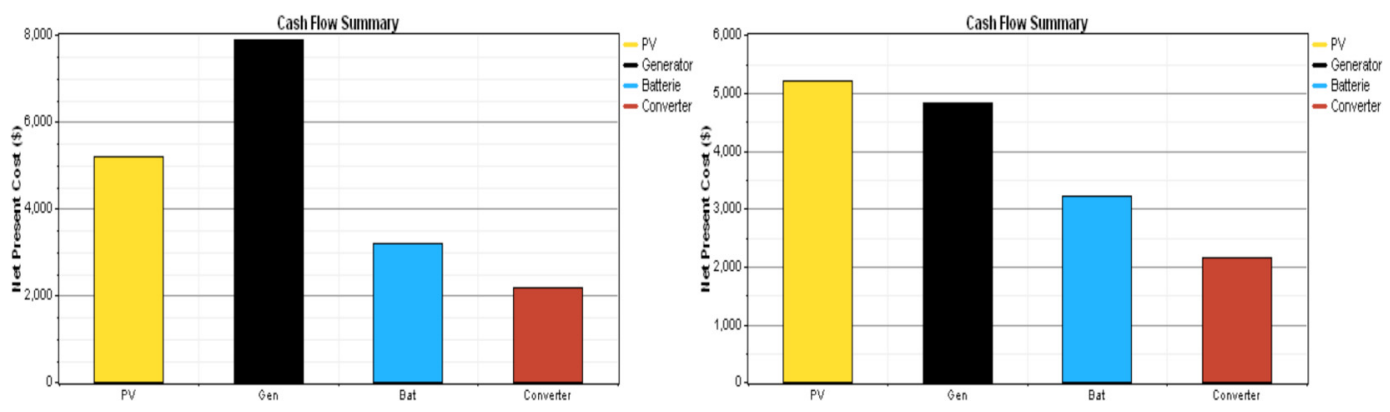

Fig. 5. Breakdown of costs of the installation.

Table 3. Emission of air pollutants.

\begin{tabular}{lll}
\hline Pollutants & \multicolumn{2}{c}{ Emissions (kg/year) } \\
\cline { 2 - 3 } & Configuration -1- & Configuration -2- \\
\hline Carbon dioxide & 3679 & 2110 \\
Carbon monoxide & 9.08 & 4.42 \\
$\begin{array}{l}\text { Unburned } \\
\text { hydrocarbons }\end{array}$ & 1.01 & 0.489 \\
Particulate & 0.685 & 0.333 \\
material & & 4.38 \\
Sulfur dioxide & 7.39 & 39.4 \\
Nitrogen oxides & 81 & \\
\hline
\end{tabular}

\subsection{Environmental analysis}

The environmental analysis of the hybrid system HOMER assesses emissions of air pollutants. Table 3 summarizes the total emission of pollutants in the three cases examined configurations.

From this table, it is possible to significantly reduce emissions of pollutants by the integration of a generator run on butane gas. According to the results, the emissions of pollutants can be reduced by approximately $50 \%$ compared to the use of a diesel generator in the hybrid system, especially emissions of $\mathrm{CO}_{2}$ and $\mathrm{CO}$ responsible for the greenhouse effect.

\section{Conclusion}

In this paper, a study relating to the design of a hybrid energy system on the scale of a house has been developed. This study takes place in four main steps, evaluation of energy demand and solar resource, evaluating energy options and the selection of the system.

Through this study, an assessment of the impact of the technology of generator and the change in the inclination angle of photovoltaic modules on production and energy savings of a hybrid energy system in the region Ghardaïa was performed. It was found that a considerable fuel savings can be carried out in photovoltaic hybrid systems with using a backup generator running on butane gas. For those areas where the price of fuel increases progressively with isolation, fuel economy is fundamental.

The results of this study can be used as reference for deployment of stand-alone photovoltaic hybrid systems to supply cost effective electricity to customers while protecting the environment in remote rural areas where solar resources are available.

\section{References}

1. S. Anjali, C. Patrick, T. Daniel, B. Martin, Accès à l'électricité en Afrique subsaharienne : retours d'expérience et approches innovantes (Agence française de développement, 2012)

2. A.B. Stambouli, Algerian renewable energy assessment: the challenge of sustainability, Energy Policy 39, 4507 (2011)

3. http://www.mem-algeria.org/fr/enr/pot.htm

4. M. Adouane, M. Haddadi, K. Touafek, S. AitCheikh, Monitoring and smart management for hybrid plants (photovoltaic-generator) in Ghardaïa, J. Renew. Sustain. Energy 6, 023112 (2014). DOI:10.1063/1.4871095

5. H.G. Beyer, T. Degner, Assessing the maximum fuel savings obtainable in simple wind diesel systems, Sol. Energy 61, 5 (1997)

6. S. Rehman, M. Mahbub Alam, J.P. Meyer, L.M. AlHadhrami, Feasibility study of a wind-pv-diesel hybrid power system for a village, Renew. Energy 38, 258 (2012)

7. J. Andrews, B Shabani, Dimensionless analysis of the global techno-economic feasibility of solar-hydrogen systems for constant year-round power supply, Int. J. Hydrog. Energy 37, $6(2012)$

8. A. Kaabeche, M. Belhamel, R. Ibtiouen, Techno-economic valuation and optimization of integrated photovoltaic/wind energy conversion system, Sol. Energy 85, 2407 (2011)

9. A. Chaurey, T.C. Kandpal, A techno-economic comparison of rural electrification based on solar home systems and PV microgrids, Energy Policy 38, 3118 (2010)

Cite this article as: Mabrouk Adouane, Ismail Tabet, Daoud Rezzak, Khaled Touafek, Sitayeb Abdelkader, Houam Yahia, Feasibility study of a hybrid plants (photovoltaic-LPG generator) system for rural electrification, Renew. Energy Environ. Sustain. $\mathbf{1}, 15(2016)$ 